\title{
A forest typology for monitoring sustainable forest management: The case of European Forest Types
}

\author{
A. BARBATI ${ }^{1}$, P. CORONA ${ }^{1} \&$ M. MARCHETTI ${ }^{2}$ \\ ${ }^{1}$ Department of Forest Environment and Resources, University of Tuscia, Italy, and ${ }^{2}$ DISTAT, University of Molise, Italy
}

\begin{abstract}
Sustainable forest management (SFM) is presently widely accepted as the overriding objective for forest policy and practice. Regional processes are in progress all over the world to develop and implement criteria and indicators of SFM. In continental Europe, a set of 35 Pan-European indicators has been endorsed under the Ministerial Conference on the Protection of Forests in Europe (MCPFE) to measure progress towards SFM in the 44 countries of the region. The formulation of seven indicators (forest area, growing stock, age structure/diameter distribution, deadwood, tree species composition, damaging agents, naturalness) requires national data to be reported by forest types. Within the vast European forest area the values taken by these indicators show a considerable range of variation, due to variable natural conditions and anthropogenic influences. Given this variability, it is very difficult to grasp the meaning of these indicators when taken out of their ecological background. The paper discusses the concepts behind, and the requirements of, a classification more soundly ecologically framed and suitable for MCPFE reporting than the three (un-informative) classes adopted so far: broadleaved forest, coniferous forest, mixed broadleaved and coniferous forest. We propose a European Forest Types scheme structured into a reasonably higher number of classes, that would improve the specificity of the indicators reported under the MCPFE process and its understanding.
\end{abstract}

Key words: Forest types, forest vegetation classification, reporting, sustainable forest management indicators

\section{Sustainable forest management and forest types}

Although sustainable forest management (SFM) is now widely accepted as the overriding objective for forest policy and practice, it is not easily defined (Shvidenko et al., 2005). Nine regional processes all over the world have been launched since the United Nations Conference on Environment and Development in Rio de Janeiro (1992) to develop and implement Criteria and Indicators (C\&I) of SFM (ECOSOC, 2004). Each of these processes has its own distinctive set of C\&I to measure progress towards SFM in particular regions and forest biomes. The C\&I for the Conservation and Sustainable Management of Temperate and Boreal Forests (The Montréal process, 1999) and the set of Pan-European (C\&I) for the Sustainable Forest Management endorsed in Europe (MCPFE, 2002; MCPFE, 2003a) adopt a 'forest types' specification to report on some SFM indicators.

What is a forest type? A comprehensive definition is: "A category of forest defined by its composition, and/or site factors (locality), as categorized by each country in a system suitable to its situation" (The Montréal Process, 1998).

At country level, several forest types schemes may exist. For instance, in Italy five major vegetation formations and 109 forest associations have been identified on a sinecological basis (Pignatti, 1998); the hierarchical landscape classification approach (Blasi et al., 2000) and synphytosociology have been applied to delineate national maps of vegetation series (Blasi, 2003). In the framework of the Italian National Forest Inventory 20 physiognomic forest types are used to classify field plots.

Forest types schemes developed for practical use in forestry are in use in most European countries. For instance, classifications based on ground layer vegetation communities are used in Finland (Cajander, 1949; Kujala, 1976) for estimating forest site productivity or in Austria (Hufnagl, 1970) for silvicultural decision making. In Denmark, forest development types are used to define long-term goals

Correspondence: A. Barbati, Dipartimento di Scienze dell'Ambiente Forestale e delle sue Risorse, Università della Tuscia, via San Camillo de Lellis snc, 01100 Viterbo, Italy. Tel.: +390761 357407. E-mail: barbati.sisfor@unitus.it 